\title{
Mestrado em Ensino: dimensões políticas e pedagógicas no contexto de formação docente em Portugal
}

\section{Master's in Teaching: political and pedagogical dimensions in the context of teaching training in Portugal}

\author{
Luana Priscila Wunsch* \\ João Batista Bottentuit Junior** \\ Marcia Maria Fernandes de Oliveira*
}

\begin{abstract}
RESUMO
Por meio de revisões sistemática de literatura e documental, o presente artigo, de cunho qualitativo, revisita as bases da política pública que estrutura os programas de Mestrado em Ensino em Portugal, nível formativo do docente da Educação Básica daquele país. Apesar de a temática não ser tão nova em âmbito de pesquisa científica, percebeu-se a relevância de observar categoricamente como a Declaração de Bolonha e sua arquitetura de formação profissional inicial atingiram a legislação educacional aplicada nesta realidade e como podem dar indicadores para se pensar a formação em mestrados profissionais no Brasil. Com um olhar para além da questão legislativa, a pesquisa foi desenhada com uma perspectiva pedagógica, verificando-se quais poderiam ser e quais já são os protagonistas dos processos nas mudanças efetivas ocorridas nas instituições formativas. Nesta trajetória foi possível perceber um objetivo comum sobre a relevância neste campo: o apoio na conscientização de um currículo inovador e promotor de
\end{abstract}

* Centro Universitário Internacional UNINTER. Programa de Pós-Graduação em Educação e Novas Tecnologias. Curitiba, Paraná, Brasil.E-mail: luana.w@uninter.com - http://orcid.org/00000002-9105-9520 E-mail: marcia.o@uninter.com - http://orcid.org/0000-0001-9755-0612

${ }^{* * *}$ Universidade Federal do Maranhão. São Luís, Maranhão, Brasil. E-mail: joaobbj@gmail. com - http://orcid.org/0000-0002-4432-0271 
qualidade da formação inicial, em que, para alcançar tal premissa, duas bases conceituais são norteadoras: conhecimento científico e práticas em contexto.

Palavras-chave: Mestrado em Ensino. Políticas portuguesas de formação docente. Declaração de Bolonha. Formação inicial docente.

\begin{abstract}
Through systematic reviews of literature and documents, this article, of a qualitative nature, revises the public policy bases that structure the Master's programs in Teaching in Portugal, the Basic Education teachers' training level of that country. Although the theme is not so new in the scope of scientific research, we considered the relevance of categorically observing how the Bologna Declaration and its architecture of initial professional training reached the educational legislation applied in this reality and how they can give indicators to think about training in Professional Master's in Brazil. With a look beyond the legislative issue, the research was designed with a pedagogical perspective, verifying who may be and who already are the protagonists of the processes in the effective changes that took place in training institutions. In this trajectory it was possible to perceive a common objective on the relevance in this field: the support in raising awareness of an innovative curriculum that promoted quality of initial training in that, in order to reach this premise, two conceptual bases are guiding: scientific knowledge and practices in context.
\end{abstract}

Keywords: Master's in Teaching. Portuguese teacher training policies. Bologna Declaration. Initial teacher training.

\title{
Introdução
}

Estudos sobre a formação inicial do professor publicados em língua portuguesa são considerados como referências em âmbito mundial (NÓVOA, 1992; ARROYO, 2009; TARDIF, 2011), centrando-se, de forma geral, em temáticas sobre as especificidades e necessidades formativas dos futuros professores.

Ao considerar a relevância de tais estudos, vê-se a relevância de se perceber como, para além da literatura, são vistas e aplicadas as políticas efetivas sobre a primeira base da prática docente nos últimos anos.

E, sob estes pontos, ao destacar a realidade específica portuguesa, esta investigação tenta perceber, para além da construção social desta etapa formativa, quais regimes possibilitam a habilitação profissional para a docência em Portugal 
e como as suas bases de ensino superior, público e privado, podem conduzir à aquisição de componentes da área educacional geral, das didáticas específicas, da área cultural, social, ética e da iniciação à prática profissional - Decreto-Lei n. ${ }^{\circ}$ 79/2014 (PORTUGAL, 2014).

Viu-se, portanto, a necessidade de se buscar modelos descritos na literatura. Dentre tantos, percebeu-se que neste âmbito três pontos destacavam-se: (i) a questão da sistematização política; (ii) a questão da sistematização institucional; e (iii) a questão da sistematização da unidade curricular, lembrando Bernstein (1988) ao relatar que é no movimento de transmissão e compreensão que será encontrada a essência do fenômeno de produção de consciência dos formandos, ou seja, como o que está fora se torna dentro, como o socioeconômico condiciona e determina o individual, como o macro e o micronível se relacionam. O conhecimento pode ser estruturado em currículo, pedagogia e avaliação (CUNHA, 2003).

Referentemente aos três pontos, os conceitos básicos sistematizados por Lundgren (1996) para a análise da mudança e da gestão educativa, constatou-se a gestão de problemas permanentes, cujas soluções se situam em tempo e contextos específicos e deveriam ser aplicadas a partir da análise de políticas curriculares, em que se identificaram quatro estratégias (PACHECO, 2000): a) Modelo de política centralista, no qual o papel determinante da administração central na concepção e operacionalização da política curricular trata-se de uma responsabilidade essencialmente política dos órgãos governamentais na implementação de orientações e programas definidos; b) Modelo de política descentralista, no qual o papel predominante dos territórios locais na contextualização da política curricular opera mediante a concepção, implementação e avaliação de projetos curriculares, que são recontextualizados em função de orientações políticas; c) Modelo de política centralista e descentralista, no qual prevalece a perspectiva normativa, porém com itens da política curricular descentralizada no nível dos discursos, mas recentralizada no nível das práticas; d) Modelo de política descentralista e centralista, no qual há predominância das componentes profissional dos atores e institucional dos territórios locais. A descentralização se verifica tanto nos discursos como nas práticas curriculares.

Dá-se, neste sentido, destaque para as estratégias "c" e "d", pois enfatizam o papel dos atores responsáveis não apenas pelo planejamento legal das normativas destes cursos, mas por sua aplicação prática, ou seja, "[...] as decisões sobre a criação de situações de aprendizado são facilitadas por essas explicações. Da mesma forma, a constante mudança da perspectiva político-econômica na sociedade influencia a percepção dos professores e suas conviç̧ões [...]" (NATIONAL COUNCIL OF EDUCATIONAL RESEARCH AND TRAINING, 2010, p. 22). 
Não restam dúvidas de que a aprendizagem é muito influenciada pelo contexto social do qual os professores provêm e, diante disso, percebe-se que é preciso fornecer uma revisão não apenas dos objetivos propostos pelos professores em sala de aula, mas, a partir de uma ênfase em seu cenário social e político, entrando, assim, a proeminência em se falar sobre a formação inicial de quem vai moderar o processo.

Assim, o cenário português vigente pode servir como exemplo a ser analisado, em especial na questão dos ciclos estruturados para a formação plena do docente, desde a sua atuação na educação infantil até o ensino médio. Uma das principais questões, neste sentido de plenitude formativa, é a integração da pesquisa com a prática didática, fato este que evidencia o processo de o Mestrado em Ensino ser, hoje, uma forte frente de formação inicial.

\section{Mestrado em Ensino em Portugal e suas políticas}

O Decreto-Lei n..$^{\circ}$ 240/2001 (PORTUGAL, 2001), relembrando as bases do Sistema Educativo português (Decretos-Lei n. ${ }^{\circ} 194 / 99$ e n. ${ }^{\circ} 6 / 2001$ ) nas quais se estabeleceu uma revisão do sistema de acreditação de cursos que confeririam qualificação profissional para a docência, fixa os princípios orientadores da organização e gestão do currículo desses níveis. De acordo com o referido regime, o professor é o profissional detentor de diplomas que certificam a formação profissional específica através de cursos que se organizam de acordo com as necessidades do respectivo desempenho profissional, com perfis de qualificação para a docência e reconhecimento, bem como padrões de qualidade da formação inicial fixados pelo então Instituto Nacional de Acreditação da Formação de Professores (INAFOP) ${ }^{1}$ para a respectiva acreditação e certificação.

Ao relacionar tais normativas, percebe-se que o desempenho profissional deste professor é considerado a partir da integração da formação inicial com a aprendizagem ao longo da vida para um "[...] desempenho profissional

1 Na sequência da alteração da Lei de Bases do Sistema Educativo, a qual veio a exigir uma formação de nível superior a todos os Educadores e Professores, criou-se o Instituto Nacional de Acreditação da Formação de Professores, INAFOP, que passou a zelar pela qualidade da formação conferida aos seus profissionais, em resposta a um documento orientador das políticas para o Ensino Superior em 1997, o qual descrevia a necessidade de criar uma instituição capaz de acreditar os cursos de formação para a docência. Assim, o INAFOP, hoje extinto, foi um organismo independente em relação ao Governo (SOUSA, 2003). 
consolidado e para a contínua adequação deste aos sucessivos desafios que lhe são colocados [...]" (PORTUGAL, 2001, p. 2). Para tanto, foi desenhado um perfil docente a partir de grandes dimensões estruturais: i) dimensão profissional, social e ética, a qual descreve o dever que este profissional tem, com apoio na investigação, na reflexão partilhada da prática educativa e no enquadramento em orientações de política educativa, de fomentar o desenvolvimento da autonomia dos alunos e a sua plena inclusão na sociedade, identificando as diferenças culturais e pessoais da comunidade educativa, valorizando todos os itens adjacentes desse processo, como assumir as questões emocionais, cívicas e deontológicas que lhe estão associadas; ii) dimensão de desenvolvimento do ensino e da aprendizagem no âmbito de um currículo, no quadro de uma relação pedagógica de qualidade, integrando, com critérios de rigor científico e metodológico, conhecimentos das áreas que o fundamentam; iii) dimensão de participação na escola e de relação com a comunidade, tendo a escola como espaço de educação inclusiva e de intervenção social, no quadro de uma formação integral dos alunos para a cidadania democrática; iv) dimensão de desenvolvimento profissional ao longo da vida, a partir da incorporação da sua formação como elemento constitutivo da prática profissional, da sua prática pedagógica, da reflexão fundamentada sobre a construção da profissão e do recurso à investigação; v) dimensão de cooperação com outros profissionais.

Assim, o Sistema Educativo português (EURYDICE, 2006) estabelece os fatores de qualificação, mobilidade e internacionalização na qual visa assegurar a preparação científica e cultural, bem como proporcionar uma formação técnica que habilite para o exercício de atividades profissionais, culturais e fomente o desenvolvimento das capacidades de concepção, de inovação e de análise crítica (PONTE, 2006; LOPES, 2007), em conformidade com os princípios da Declaração de Bolonha na criação de condições para a aprendizagem ao longo da vida, na adoção do modelo de organização do Ensino Superior em ciclos, na transição de um sistema de ensino baseado na transmissão de conhecimentos para um sistema baseado no desenvolvimento de competências e na adoção do sistema europeu de créditos curriculares.

Já com o Decreto-Lei n. ${ }^{\circ}$ 43/2007 (PORTUGAL, 2007) atribuiu-se prioridade ao desafio da qualificação de um corpo docente português de qualidade a partir da revisão das condições de atribuição de habilitação para a docência com a definição e verificação de cumprimento dos currículos nacionais, destacando aqui a definição das condições necessárias à obtenção de habilitação profissional para a docência num determinado domínio. $\mathrm{Na}$ delimitação de qualidade dos domínios de habilitação para a docência verificase uma maior abrangência de níveis e ciclos de ensino, a fim de tornar possível a mobilidade dos docentes entre eles. 
Para a docência na educação pré-escolar e nos ensinos básico e secundário português, segue-se o Decreto-Lei n. ${ }^{\circ}$ 79/2014 (PORTUGAL, 2014), substituindo os modelos de formação então em vigor por um modelo sequencial, organizado com estruturas curriculares do ciclo de estudos conducentes ao grau de licenciado em Educação Básica, distribuído pelas áreas de docência, educacional geral, didáticas específicas e iniciação à prática profissional; do ciclo de estudos conducentes ao grau de mestre nos domínios da Educação Pré-Escolar, $1 .{ }^{\circ}$ Ciclo do Ensino Básico e 2. ${ }^{\circ}$ Ciclo do Ensino Básico, distribuído pelas mesmas áreas, contudo a prática, agora, não é mais inicial e sim de ensino supervisionada.

Neste sentido, a titularidade da habilitação profissional para a docência é conferida a quem obtiver tal qualificação através de uma licenciatura e de um subsequente Mestrado em Ensino, no domínio específico em que irá lecionar.

A partir de então, a referência fundamental da qualificação para a docência é o desempenho esperado dos docentes no início do seu exercício profissional, segundo aquele normativo, bem como a necessidade de adaptação do seu desempenho às mudanças decorrentes das transformações emergentes na sociedade, na escola e no papel do professor, da evolução científica, tecnológica e dos contributos relevantes da investigação educacional.

Assim, estes fatores confirmam que, em muitos casos, "[...] a elaboração de um plano se limita a um repertório de matérias, disciplinas e créditos [...]" (DÍAZ, 2003, p. 113), cabendo ao órgão institucional local a responsabilidade para administrar um currículo que, nesta lógica, considere a quantidade de horas perante a qualidade de participação dispensada nos cursos, considerando que os formandos não aprendem apenas na instituição.

Para a melhoria do ensino universitário, em geral, que vem ao encontro desta conjuntura, buscar confluência entre o conhecimento e a investigação implica em uma distinção entre conhecimento técnico e conhecimento técnico inteligente. O primeiro deriva-se de forma direta por meio de tarefas que se exige, de quem as desempenha, uma rotina necessária em um determinado contexto. Já no segundo, é necessário demonstrar a compreensão da situação com capacidades de discernimento das ações realizadas. A partir destes dois pontos, percebe-se que os sistemas de formação inicial docente ainda são projetados em torno de tais aprendizados, verificando-se que o desafio é tentar criar oportunidades não apenas de transmissão, mas de desaprender e reaprender, em seguida (WHEELER, 2012).

A organização curricular apresenta-se integrando atividades e unidades curriculares que colaboram para a formação do professor, com o conhecimento sendo tratado de forma integrada, aberta, flexível (BORGES, 2010), atualizada, interdisciplinar, facilitando e incentivando os mais diversos modos de integrar teoria e prática, universidade e situações profissionais, unidades básicas e profissionalizantes (MASETTO, 2005). 
É preciso sublinhar que pensar na formação docente se refere a: (a) não ser uma prática individualizada, mas sim um processo de escuta, de observação e de análise, (b) exigir tempo e condições que, muitas vezes, não existem nas escolas, sugerindo-se uma relação forte entre as escolas e o mundo universitário, por razões teóricas e metodológicas, e (c) implicar formas de divulgação pública dos resultados (NÓVOA, 2002, p. 259), pois “'[...] o conhecimento não representa uma imagem verdadeira da realidade, mas é uma experiência perceptiva da realidade, um objeto artificial [...]" (NYGAARD; HØJLT; HERMANSE, 2008, p. 36).

Nesta experiência da realidade que deve ser proposta eficazmente nos currículos nestes âmbitos de formação docente, a construção dos planos de estudo exige determinar alguns aspectos: (a) a seleção de conhecimentos, habilidades, atitudes e valores que constituem o perfil acadêmico e profissional da titulação; (b) a delimitação e justificação das unidades curriculares em torno das quais se estruturam os processos de ensino e aprendizagem; (c) a organização das propostas inovadoras que oferece o plano tanto em relação aos conteúdos como aos métodos ou os sistemas de planejamento e implantação.

A mediação pedagógica, por meio desta articulação, busca abrir um caminho a novas relações com materiais, com o próprio contexto, com outros contextos, com seus companheiros de aprendizagem, incluindo o formador, consigo mesmo e com o seu futuro trabalho em sala de aula. E com base no conhecimento adquirido, os formandos podem reconhecer suas habilidades analisando os desafios das escolas nas quais atuaram. E as unidades curriculares propostas em nível mais amplo não irão constituir, assim, ações pontuais, mas planos, programas e projetos capazes de orientar e de fornecer os meios necessários ao alcance dos objetivos da educação básica, objetivo final da proposta do curso.

Nesta linha, tais situações de informação e de interação a serem promovidas podem sugerir que os formandos não aprendam de única forma, impondo uma coerência ao pensar em técnicas e ações, logicamente coordenadas para dirigir a aprendizagem do futuro aluno para uma criticidade na sua aprendizagem.

Verifica-se, portanto, que pensar nos objetivos das unidades curriculares é: (a) refletir sobre os objetivos propostos, em sua globalidade, para dar base ao todo; (b) analisar a situação do "como", "com quem" e "onde" se realizará a aprendizagem; (c) partir do concreto, pensando como usar da melhor forma recursos e novos conceitos perante a realidade que se irá encontrar na escola; (d) pensar em um ensino mais variado, afinal a rotina já se mostrou má companheira do processo de formação docente, pois ela nunca é encontrada na escola posteriormente. 
Entende-se, portanto, que os conteúdos destas unidades curriculares integradoras deveriam ser ponderados com uma composição de múltiplas perspectivas. É fundamental ter presente métodos e procedimentos que validem um paradigma com perspectivas que venham ao encontro com as perspectivas profissionais dos futuros professores por meio das suas experiências pessoais e sociais (TORRES, 2007), centradas na informação, na pessoa, na tarefa, nas atitudes e expectativas.

Ainda neste sentido, Quintás (1997) relatou que o processo de organização da formação docente deve seguir aspectos que ainda estão coerentes com a realidade atual, como se pode verificar nas descrições: âmbito da realidade; do perceber o redor; e do entender que um professor não fica circunscrito por suas dimensões corpóreas, afinal o mesmo desde a entrada na sua formação inicial engloba certo campo em diversos aspectos, como o estético, ético, profissional, religioso. Tais significações podem ser consideradas, por exemplo, como um conjunto de experiências (ARGUDÍN, 2007) que constitui um processo de integração de uma antecipação do futuro trabalho, não como reproduzir, mas sim com o recordar do passado como contexto social. A formação docente, assim como a prática em sala de aula, precisa cada vez mais de um pensamento prospectivo, não de perspectiva de adivinhar o futuro, mas de agir estrategicamente, no presente, para que o futuro possa ser o resultado de uma escolha, de uma reinvenção de processo formativo (ENOCHSSON, 2009; CANÁRIO, 2006).

Assim, se pode dizer que o currículo é considerado como constitutivo dos cenários nos quais o desenvolvimento pessoal deste professor se forma, o que significa que não expõe somente um conjunto de enunciados prescritos de perfis profissionais e de competências a serem desenvolvidas, mas também um enredo de proposições que contextualizam as possibilidades da ação. Dentre as importantes metas da formação, portanto, entra o desenvolvimento de competências docentes como norteadoras perante este enredo contextualizado para responder a uma necessidade social (PRENDES; CASTAÑEDA; GUTIÉRREZ, 2010) dirigida para a adaptação ao mercado e como alicerce para que este docente se sinta integrado no cenário da sua profissão.

Já no aspecto da regulação, as instituições formativas e os formadores precisam estar preparados para alertar das questões legais da má utilização das Tecnologias de Informação e Comunicação (TIC), em especial nas ferramentas de comunicação e socialização.

A natureza transcultural da Web também cria problemas de controle legislativo e/ou público, com os temores de que a cultura local possa ser ameaçada pela cultura internacional dos países desenvolvidos, embora o uso da Internet, do ensino aberto e à distância sejam predominantemente representados no ensino superior, também começando a ser utilizados em escolas (UNESCO, 2002, p. 11). 


\section{Design Metodológico}

Em consideração a uma análise sobre a formação inicial docente em Portugal tem-se claro a necessidade em considerar as recomendações de autores cientes desta realidade.

Sob este cenário, optou-se por seguir a indicação de duas saídas principais: uma revisão da literatura de pesquisa e uma revisão das políticas internacionais e nacionais, pelas quais surgiram uma preocupação com o aspecto da elevada quantidade de publicações de formação docente, porém poucas em relação à formação inicial docente, fato que comprovou a importância da revisão da literatura em um projeto científico na área da educação, especificamente.

Abordou-se, portanto, um tipo de texto que discutiu informações produzidas como componente base review (TAYLOR, 2002). Assim, após situar a problemática e os objetivos, tornou-se preciso "[...] reunir e analisar, o melhor possível, o que já se conhece sobre o assunto, as informações existentes [...]" (ALMEIDA; FREIRE, 2008, p. 40) com o intuito de fundamentar o estudo, partilhar os resultados de outros estudos que estão "[...] intimamente relacionados e preencher lacunas e ampliando os estudos anteriores [...]" (CRESWELL, 2011, p. 51) a este.

No âmbito qualitativo deste estudo, a revisão da literatura foi fonte de apoio à estruturação para se chegar à fonte primária da temática: os mestrados em ensino e a necessidade de perceber o contexto no qual estão inseridos. Para tal verificação, foram consultados documentos oficiais como normativas, diretrizes, despachos e leis para perceber as origens, finalidade e público (GRIX, 2002), o que foi fundamental para o processo.

A análise documental, prática muito utilizada na investigação educacional e com o fim concreto de ir além do contexto de produção textual (MOGALAKWE, 2006), teve papel fulcral na investigação nomeadamente em duas bases: primárias e secundárias. Os documentos aqui considerados primários foram os diretamente ligados à estruturação do mestrado em ensino e os secundários, ao cenário português e europeu.

Outro ponto dessa fase foi um exame das políticas internacionais, principalmente em âmbito europeu, e nacionais em matéria dos mestrados em ensino como formação inicial de professores. Como parte deste exercício, uma variedade de documentos foi examinada e analisada, incluindo relatórios oficiais, artigos, a Declaração de Bolonha e suas diretrizes como estrutura para a formação e os mestrados em ensino em Portugal. 
De tal modo, tomando por base o desenho da análise documental realizada nesses países, decidiu-se efetivar uma estrutura similar perante a realidade portuguesa, a partir da recolha dos seguintes documentos, que foram minuciosamente analisados: (a) documentos europeus que envolvessem a temática; (b) documentos do ponto de vista legislativo do Ministério da Ciência, Tecnologia e do Ensino Superior; (c) currículos e planos de estudo das IES participantes da pesquisa.

Tornou-se indispensável verificar os referidos documentos na tentativa de averiguar como se poderia proceder à administração de tais formações. Para torná-los inteligíveis, todos os documentos foram catalogados em pastas durante o prosseguimento (RAJU, J.; RAJU, R. 2006), tendo como critério estabelecido para tal organização a fonte documental descrita em "Relatórios, Diretrizes e Legislações" deste relatório, referindo uma “[...] operação pela qual se identifica o documento em função de suas características formais e de seu conteúdo, tais como o autor, o título, o local de publicação, o editor, o ano de publicação, assim como o tema da obra [...]" (SÁNCHEZ LUNA, 2004, p. 83).

As leituras e interpretação tiveram um papel central nesta fase. Para cada documento foi criada uma ficha de leitura contendo resumo, referência da publicação, além de algumas transcrições de trechos que foram utilizados posteriormente na análise dos dados.

\section{Formação inicial dentro da universidade}

A legislação educacional portuguesa vigente explicita que é necessário que um professor obtenha a titulação de mestre em ensino para atuar como docente da sua área de graduação nos níveis básico e secundário, vindo ao encontro da constante preocupação europeia no âmbito da formação profissional.

Para melhor entender este processo é necessário, num primeiro plano, abranger o cenário europeu atual da qualificação profissional docente. A Comunidade Europeia como entidade transnacional (CONSELHO DE REITORES DAS UNIVERSIDADES PORTUGUESAS, 2000) planejou, nas últimas décadas, iniciativas no campo da educação propondo diferentes programas que envolvessem dimensões econômicas, sociais e laborais.

Verifica-se que, historicamente, na formação profissional a inquietação foi em dois sentidos: formação universitária e formação contínua. Fatores estes que suportam, até hoje, a formação dos professores nesta realidade (Despacho n. ${ }^{\circ}$ 6967/2010), em uma tentativa de assegurar a qualidade da educação básica, segundo relatórios internacionais (UNIVERSIDADE DE LISBOA, 2010). 
No sentido de marcar uma mudança em relação às políticas ligadas ao ensino e na procura de estabelecer uma Área Europeia de Ensino Superior, foi a partir do comprometimento dos países signatários em promover reformas de seus sistemas de ensino que se estruturou a Declaração de Bolonha (1999). Com objetivo de elevar a competitividade internacional do sistema europeu do Ensino Superior, o referido documento promoveu a aquisição de um grau de atração internacional semelhante ao das suas tradições cultural e científica (EUROPEAN COMMISSION, 1999). Assim, é possível encontrar nesta diretriz indicadores que vêm ao encontro de estratégias formativas (SOUSA, 2003) docentes referenciadas em documentos portugueses recentes (por exemplo, o Plano Tecnológico da Educação), tais como: inovação e desenvolvimento curricular; cooperação interinstitucional; mobilidade de estudantes, docentes e investigadores; e programas integrados de estudo, de formação e de investigação.

Outros aspectos a serem considerados são o incentivo à mobilidade por etapas e a livre circulação, com particular atenção ao acesso a oportunidades de estudo e de estágio aos serviços relacionados, podendo ser comparáveis à formação inicial dentro da universidade no sentido da cooperação europeia na avaliação da qualidade e em vista a desenvolver critérios, metodologias, empregabilidade e competitividade.

Um dos aspectos mais discutidos da Declaração de Bolonha (1999) e que entrou como ponto central para a reformulação da formação docente foi a adoção do sistema baseado em três ciclos de estudos: $1^{\circ}$ ciclo, com a duração mínima de três anos, designado em Portugal como Licenciatura; $2^{\circ}$ ciclo, com a duração de um ano e meio a dois (excepcionalmente um ano) - Mestrado; $3^{\circ}$ ciclo - Doutoramento.

Com esta estrutura é imperativo estabelecer um sistema de créditos transferíveis e acumuláveis (ECTS), comum aos países europeus, podendo também ser adquiridos em contextos de ensino não superior, incluindo a aprendizagem ao longo da vida, desde que sejam reconhecidos pelos estabelecimentos de acolhimento (EUROPEAN POLITICAL CONTEXT, 2011; EUROPEAN COMMISSION, 2001, 2002, 2003).

Em 2001, os ministros de educação dos países da União Europeia adicionaram à Declaração de Bolonha (EUROPEAN COMMISSION, 2001), entre outras, duas linhas de ação que condizem com os pressupostos formativos, designadamente: a promoção da aprendizagem ao longo da vida e o maior envolvimento dos estudantes na gestão das Instituições de Ensino Superior (EUROPEAN POLITICAL CONTEXT, 2011; EUROPEAN HIGHER EDUCATION AREA, 2010). Estas premissas podem ser comparáveis à formação docente, inclusive para a promoção da mobilidade nos sentidos da diversidade cultural e linguística. Já no que diz respeito à formação inicial 
dentro da universidade, se destaca o apoio para o Ensino Superior (EUROPEAN COMMISSION, 2001) com programas que conduzem a orientações diferentes e perfis diversificados de forma a responder às necessidades individuais, acadêmicas e laborais.

Em 2003, os ministros da educação firmaram o compromisso de estabelecer medidas de certificação de qualidade, de implementação do sistema de dois ciclos no âmbito da formação universitária (Graduação e Mestrado) e do reconhecimento de graus e duração dos cursos.

Em 2005 (EUROPEAN COMMISSION, 2005), as autoridades europeias mais uma vez reafirmaram o compromisso com Bolonha e destacaram a importância das universidades (EUROPEAN UNIVERSITY ASSOCIATION, 2002) para a colaboração entre o Ensino Superior (EUROPEAN LIFELONG LEARNING INDICATORS, 2008), empregadores e outros parceiros. Os propósitos das ações indicadas para tais ciclos, em termos gerais, reforçam a necessidade específica de readequação do sistema da qualificação docente (EUROPEAN HIGHER EDUCATION AREA, 2010). A partir do surgimento de programas de titulação em áreas disciplinares do ensino básico, intencionou-se a interconexão efetiva de um sistema de redes apropriado ao processo de inovação educacional em que se vive.

Com tais diretrizes e com a possibilidade de uma adaptação contextualizada na sociedade globalizada do conhecimento (UNESCO, 2009), nunca se esteve tão convencido de "[...] que o ensino superior é um dos principais impulsionadores do desenvolvimento econômico e social e da inovação em um mundo cada vez mais orientado para o conhecimento [...]" (EUROPEAN HIGHER EDUCATION AREA, 2010, p. 2). Assim, com maior apoio profissional para este compromisso, programou-se a European Higher Education Area (EHEA) para os diferentes ciclos, apelando a todos os atores envolvidos para facilitar um ambiente inspirador de trabalho e aprendizagem e promover a aprendizagem centrada no aluno, como forma de capacitá-lo em todas as formas de educação.

Portanto, a partir deste cenário (intensamente questionado) cria-se a necessidade de estruturar programas de estudo para garantir a projeção (BERAZA, 2008) e a ampliação da participação de todos os agentes envolvidos nas formações profissionais (CABERO, 2006), com a perspectiva de atrair uma procura diversificada e intensa de futuros professores, com características de "pós-secundário", "alunos adultos" e profissionais que buscariam um upgrade para o conhecimento científico e/ou garantia de trabalho (EUROPEAN UNIVERSITY ASSOCIATION, 2008).

Apesar de diferentes formulações nos países signatários da Declaração de Bolonha (RUIZ; PARÉS, 2005), o Mestrado, especificamente, pode ter como diretrizes os itens descritos no Quadro 1 e cada país tem a autonomia para 
dividi-los em "pré-master, master, pós-master" e "mestrado profissionalizante". Os estudos do $2^{\circ}$ ciclo podem ser promovidos por questões relativas a uma determinada área ou por interface de diferentes setores, em uma vertente chamada vocacional (EUROPEAN QUALIFICATIONS FRAMEWORK, 2008).

\section{QUADRO 1 - ESTRUTURA BASE DOS MESTRADOS NA UNIÃO EUROPEIA}

\begin{tabular}{l|l|l}
\hline Conhecimentos & Habilidades & Competências \\
\hline - Conhecimentos altamente & - Capacidade especializada para & - Gerir e transformar \\
especializados, alguns estão na & resolver problemas no âmbito & contextos de trabalho ou \\
vanguarda do conhecimento em & da investigação e / ou inovação, & estudo que são complexos, \\
um campo de trabalho ou estudo,, & a fim de desenvolver novos & imprevisíveis e que exigem \\
como base para o pensamento & conhecimentos e procedimentos & novas abordagens estratégicas. \\
original e/ou pesquisa. & e integrar os conhecimentos de & - Assumir a responsabilidade de \\
- A consciência crítica de & diferentes áreas. & contribuir para o conhecimento \\
questões do conhecimento & & e prática profissional e/ou para \\
no campo e na interface entre & & rever o desempenho estratégico \\
diferentes campos. & & \\
\hline
\end{tabular}

FONTE: com base em European University Association - EUA (2009).

A partir destas três colunas criaram-se indicadores para todos os níveis do Ensino Superior, sendo o mestrado descrito conforme disposto no Quadro 2:

QUADRO 2-INDICADORES EUROPEAN QUALIFICATIONS FRAMEWORK(EQF)

\begin{tabular}{|c|c|c|c|c|}
\hline Nível & Conhecimentos & Habilidades & Competências & Exemplo \\
\hline 7 & $\begin{array}{l}\text { - Conhecimentos } \\
\text { altamente } \\
\text { especializados, } \\
\text { alguns estão na } \\
\text { vanguarda do } \\
\text { conhecimento } \\
\text { em um campo de } \\
\text { trabalho ou estudo, } \\
\text { como base para o } \\
\text { pensamento original } \\
\text { e/ou pesquisa. }\end{array}$ & $\begin{array}{l}\text { - Capacidade } \\
\text { especializada para } \\
\text { resolver problemas } \\
\text { no âmbito da } \\
\text { investigação e/ou } \\
\text { inovação, a fim de } \\
\text { desenvolver novos } \\
\text { conhecimentos e } \\
\text { procedimentos. }\end{array}$ & $\begin{array}{l}\text { - Gerir e transformar } \\
\text { contextos de trabalho } \\
\text { ou estudo que são } \\
\text { complexos, imprevisíveis } \\
\text { e que exigem novas } \\
\text { abordagens estratégicas. } \\
\text { - Assumir a } \\
\text { responsabilidade de } \\
\text { contribuir para o } \\
\text { conhecimento e prática } \\
\text { profissional. }\end{array}$ & $\begin{array}{c}\text { Mestrados } \\
\text { profissiona- } \\
\text { lizantes e } \\
\text { acadêmicos. }\end{array}$ \\
\hline
\end{tabular}

FONTE: com base em European University Association - EUA (2009).

É interessante notar o reconhecimento da conscientização da pesquisa crítica com questões entre diferentes campos de especialidades perante a resolução de problemas atuais. Portanto, gerir e transformar contextos de estudo ou de trabalho que são complexos e imprevisíveis exige, segundo estes documentos, novas abordagens estratégicas com contribuição para a 
prática profissional na formação inicial, na formação em serviço/prática e no desenvolvimento profissional contínuo em ambientes escolares (EUROPEAN QUALIFICATIONS FRAMEWORK, 2008).

Ao relacionar estas abordagens, a formação inicial docente pode ser encarada na Europa como "[...] atividade que desenvolve habilidades de um indivíduo, competências, conhecimentos e outras características como professor [...]" (ENOCHSSON, 2009, p. 49). É a partir desses aspectos destacados que se torna pertinente a verificação da aplicação destes pressupostos no cotidiano formativo de docentes da educação básica.

Atendendo aos objetivos desta investigação, a seguir é descrito como estas diretrizes influenciaram a estrutura que é aplicada na formação de profissionais de educação em Portugal, especificamente nos mestrados em ensino.

Pensar na organização da formação inicial docente como política pública é pensar em um fator que pode ser estruturado em longo prazo, é pensar na formação consistente de um profissional que deverá olhar para o seu aluno como um cidadão de direitos iguais perante a lei, com direito à boa formação e integração social (NATIONAL COUNCIL FOR TEACHER EDUCATION, 2009). Nesse sentido, é importante ponderar um currículo formativo que atenda ao aperfeiçoamento de um novo professor que reflita sobre como se dá constitucionalmente a construção da infância, bem como suas dimensões perante a política associada ao seu posicionamento e desenvolvimento na sociedade.

Para refletir sobre este aspecto político como alicerce da reflexão social da formação inicial docente, é evidente pensar na função do segundo ponto a ser destacado perante a estrutura curricular desta, a qual evidencia a função da instituição formadora na elaboração do currículo formativo. Neste sentido, o currículo é uma concepção organizativa nuclear. Especificamente como base da profissionalização docente, é possível verificar algumas lacunas na estrutura de muitos cursos neste domínio e que ora são de responsabilidade da lei vigente, ora da instituição formadora:

a) cursos que não possuem identidade, que em momentos formam especialistas plenos da área e em outros momentos formam um professor;

b) cursos que ainda são concebidos considerando que uma formação teórica sólida garante uma prática consequente;

c) inconsistência nas propostas do estágio, com inviabilidade de orientações efetivas dos alunos e a modulação das turmas com número excessivo de alunos a serem orientados e acompanhados;

d) propostas de formação que raramente incluem poucas inovações na articulação com as atuais necessidades e desafios da educação básica, como a inclusão, a diversidade, a violência, o que mantém a formação centrada no domínio acadêmico dos conhecimentos específicos, mais articulados com a licenciatura plena que na docência. 
Por tais mudanças entende-se, portanto, a relação entre o conhecimento nos domínios de ensino, conteúdo científico, humanístico, tecnológico ou artístico da área curricular da docência, assim como por meio da definição de um número de créditos necessários. Nesta linha, os ciclos de estudos devem ser organizados incluindo os seguintes componentes: (a) formação educacional geral; (b) didáticas específicas; (c) iniciação à prática profissional; (d) formação cultural, social e ética; (e) formação em metodologias de investigação educacional e (f) formação na área de docência.

$\mathrm{O}$ trabalho do formador precisa centrar-se nas oportunidades de oferecer aos formandos uma prática voltada para a realidade da sociedade. É necessário buscar no processo de ensino-aprendizagem uma relação " [...] capaz de aprender ao mesmo tempo que ensina, de discutir e questionar os problemas existentes nas escolas e tentar explicá-los a partir de constatações feitas em cada realidade concreta [...]" (NICKEL, 2003, p. 63).

Ao relatar a prática profissional, pode-se fazê-lo a partir de duas perspectivas (FORMOSINHO, 2001): (a) inicial: iniciando gradualmente pela observação de contextos, após observação de classes e de alunos, assumindo a forma de prática docente pontual nas turmas; (b) final: mais conhecida como estágio, é a fase da prática acompanhada e orientada, em que o formando desempenha a ação docente em contexto global real. O objetivo principal não é ensinar uma especialização técnica, mas também oferecer uma educação, podendo ter diferentes níveis de habilidade.

O relacionamento entre as situações e momentos escolares e as situações de trabalho implica, no caso da formação inicial dos professores, que as escolas sejam encaradas como lugares fundamentais de aprendizagem profissional e não como meros locais de aplicação. A aceitação deste pressuposto sugere que o contato próximo aos contextos de trabalho seja realizado o mais precocemente possível e esteja presente ao longo de todo o percurso de formação inicial, não como etapa final. Só desta forma é possível “[...] favorecer um percurso interativo entre formação e trabalho que permite o movimento duplo de mobilização, para a ação [...]" (CANÁRIO, 2000, p. 41).

Contudo, o que neste ponto se quer destacar não seria a prática profissional apenas como unidade curricular, mas como base para o desenvolvimento da autonomia profissional e de seus contextos.

Falar sobre formação de professores implica falar de um investimento na relação e desenvolvimento de projetos nas escolas, nas quais estes futuros professores irão atuar. $\mathrm{O}$ desafio é integrar no cotidiano do curso uma prática que envolva os formandos, formadores, professores das escolas e alunos em ações de transformação educativa. 
No campo da formação inicial docente, busca-se conhecer como o professor é formado nas e pelas instituições escolares (SANTOS, 2000). Durante a prática, é possível compreender como a sua história de vida e profissional se entrecruzaram, modelando seus comportamentos, suas perspectivas profissionais, sua visão, concepções sobre a educação, o processo de ensino e a organização do trabalho escolar.

Tal transformação da prática docente pode ser possível a partir de um movimento contido em uma nova visão da realidade, pela qual se buscam novas formas de organizar as relações entre os formandos e o mundo do trabalho. Dentre as principais bases para uma prática efetiva perante esta perspectiva deveriam constar: (a) participação na elaboração do projeto pedagógico e dos planos de ensino para perceber aspectos éticos e metodológicos; (b) participação nas planificações das aulas; (c) participação na escolha dos recursos utilizados; (d) participação em reuniões da comunidade escolar; (e) participação em atividades que envolvam a integração familiar; (f) participação no processo avaliativo.

Os desafios da iniciação da prática profissional, neste sentido, são cada vez maiores e mais complexos. Com a visão sistêmica ou holística, os formadores precisam ainda instigar seus formandos para a recuperação de valores perdidos entre universidade e escola. Ora, por esta se tratar de uma prática social, conscientemente desenvolvida, só pode ser entendida "[...] a partir de uma definição da sua área problemática que é a relação teoria e prática. Ela não existe sem algum conhecimento sobre a situação de atuação e alguma ideia do que seja o ensino [...]" (PINTO, 2001, p. 55).

Logo, o seu objetivo não se resume, apenas, à formação de homens e mulheres que possuam um forte sentido de cidadania e se responsabilizem pela criação de uma sociedade mais justa e mais humana, mas também à missão de servir a comunidade e o grande público. Já a análise das funções da universidade constitui um aspecto importante para revelar as relações e articulações profundas entre esta e a sociedade. Afinal, a transformação que se vê dá-se pela necessidade de atravessar, quer os sistemas de "[...] formação quer o próprio mundo do trabalho, [os quais] tornaram ultrapassada a maneira de ver a educação, nomeadamente no que diz respeito ao papel e perspectivas do Ensino Superior no campo da formação profissional [...]" (CANÁRIO, 2000, p. 33).

Outro ponto a ser considerado perante o tema da prática pedagógica é o que se refere ao distanciamento entre teoria e prática. Situação esta que se caracteriza pela forte influência do paradigma da racionalidade técnica, o qual privilegia somente o saber científico (BEHRENS, 2008).

A articulação dialética entre os saberes adquiridos na ação e os saberes formalizados na teoria enfatiza a reflexão na ação (SCHÖN, 1983) como processo de conhecimento, representa o aspecto principal da evolução teórica e epistemológica que consistiu em estabelecer uma ruptura com uma epistemologia da prática que a reduz a um estatuto de aplicação. 
Torna-se pertinente, a partir dessas descrições, refletir sobre a mudança que se exige na formação de professores não apenas na coordenação da prática, mas em revisões paradigmáticas, na inovação do pensamento sobre ela (PALMERO, 2011), em uma atitude de diálogo com os problemas e frustrações que hoje são visíveis (ALARCÃO, 2001; NÓVOA, 2007), fator este que não pode estar alheio ao processo da formação docente.

Nesta linha, mostra-se a articulação destes pontos, dando especial destaque às tecnologias da informação e comunicação como recursos que podem promover a integração dos conceitos pedagógicos práticos e inovadores, destacados até aqui, referenciados ao futuro professor da escola básica.

\section{Considerações finais}

Normativas, leis e diretrizes europeias e portuguesas fizeram com que se percorresse um caminho no que abrange a temática aqui tratada. Simultaneamente, foi identificada uma grande necessidade de investigação sobre formação inicial docente e tecnologias nesse contexto. A questão de investigação foi, a cada etapa do estudo, recebendo mais respostas afirmativas e, com isto, a complexidade de organização deste estudo ganhou mais força. Um dos fatores mais impressionantes deste percurso foi perceber como a formação contínua de professores é pensada, estruturada e repensada no cenário mundial e como se reflete sobre a base de todo este processo, de onde vêm e como chegam os professores aos cursos de formação.

Organizar projetos de formação docente atualmente, tomando como referência os perfis do professor em diferentes áreas do conhecimento, é uma tarefa de pressupostos nada lineares em sua composição, como se pôde perceber. A partir dos resultados aqui obtidos, verificou-se a crença sobre a necessidade de uma revisão de alguns pontos do programa formativo, por meio de uma atualização/modernização do que hoje é proposto aos futuros professores, especialmente no que diz respeito à integração das tecnologias de informação e comunicação. Este tipo de preocupação já tinha sido verificado no estudo de implementação de competências tecnológicas, por exemplo, em Portugal (COSTA et al., 2008, 2009), no qual foi relatado que a maioria dos professores parecia não estar " [...] adequada à continuação da formação após o ingresso na atividade profissional, nem tampouco, o que se lhes afigura ainda como mais grave, parece preparar os futuros professores para utilizarem os recursos tecnológicos em contexto de ensino e aprendizagem [...]" (COSTA et al., 2009, p. 9). 
Durante o presente estudo foi possível perceber um objetivo comum sobre a relevância neste campo: o apoio na conscientização de um currículo inovador e promotor de qualidade da formação inicial.

Para alcançar tal premissa, duas bases conceituais apareceram como norteadoras: conhecimento científico (CC) e práticas em contexto (PC), ambas carentes de uma revisão estrutural. Não se faz necessário dizer que o domínio científico de uma determinada área do conhecimento é absolutamente essencial, pois sem esta base o resto é nulo (NÓVOA, 2009). O que aqui é proposto, sob a configuração atual das políticas europeias e portuguesas de qualificação profissional docente, é ter em consideração que a questão principal do processo formativo está centralizada nos conhecimentos que o professor necessita dominar para poder ensinar, e que deve possuir para alcançar um estádio de competência na sua prática, tendo como ponto de intersecção o conhecimento pedagógico do conteúdo (CPC ou PCK, Pedagogical Content Knowledge no original), descrito por Shulman (1987), e que tem como base um programa contextualizado, atual e dinâmico da formação dos professores neste processo formativo.

Nas fases desta pesquisa, tais perspectivas inovadoras também surgiram relativamente ao que se pretende de uma universidade como instituição formativa, percebendo-se a necessidade de se formar um professor que seja cada vez mais um profissional capaz de se adaptar às características e desafios das situações singulares em função das especificidades dos alunos, dos contextos escolares e sociais (PORTUGAL, 2007). Este tipo de documento normativo serviu como referência para a definição do perfil hoje exigido do candidato aos cursos de mestrado, que contempla, entre outras características, os conhecimentos e competências na sua área de especialidade, capacidades gerais de pesquisa e análise crítica de informação, bem como de comunicação, utilizando uma variedade de linguagens e suportes, incluindo as tecnologias de informação e comunicação.

Aquelas características, segundo os resultados apontados neste estudo, precisam ser revisitadas considerando o paradigma inovador e contextualizado em que se situam os formandos e formadores. Afinal, é preciso levar em consideração as especificidades dos professores que necessitam desta qualificação, que muitas vezes não condiz com a realidade em que vão lecionar. As tecnologias, neste sentido, têm surgido como um elemento-chave para reformas educacionais e inovações nas escolas da educação básica, sugerindose assim a relevância de integrar tais recursos tecnológicos na formação e na qualificação de professores para estes níveis de ensino. 


\section{REFERÊNCIAS}

ALARCÃO, Isabel. Professor-investigador: que sentido? Que formação? Cadernos de Formação de Professores, Aveiro, v. 1, p. 21-30, 2001. Disponível em: http://www.educ. fc.ul.pt/docentes/jponte/sd/textos/alarcao01.pdf. Acesso em: 19 jul. 2020.

ALMEIDA, Leandro; FREIRE, Teresa. Metodologia da investigação em psicologia e educação. 5. ed. Braga: Psiquilibrios, 2008.

ARGUDÍN, Yolanda. Educación basada en competencias: nociones y antecedentes. Sevilla: Eduforma, 2007.

ARROYO, Miguel Gonzalez. Ofício de mestre: imagens e auto-imagens. 11. ed. Petrópolis: Vozes, 2009.

BARRETO, Raquel Goulart. Tecnologia e educação: trabalho e formação docente. Educação e Sociedade, v. 25, p. 1181-1201, 2004.

BEHRENS, Marilda Aparecida. Projetos de aprendizagem colaborativa num paradigma emergente. In: MORAN, José Manuel; BEHRENS, Marilda Aparecida; MASETTO, Marcos Tarcisio. Novas tecnologias e mediação pedagógica. 14. ed. Campinas: Papirus, 2008. p. 67-132.

BERAZA, Miguel A. Zabalza. Innovación en la enseñanza universitaria: el proceso de convergencia hacia un Espacio Europeo de Educación Superior. Educação, Porto Alegre, v. 31, n. 3, p. 199-209, out. 2008.

BERNSTEIN, Basil. Poder, educación y conciencia: sociologia de la transmisión cultural. Santiago: Cide, 1988.

BORGES, Lívia Freitas Fonseca. Um currículo para a formação de professores. In: VEIGA, Ilma Passos Alencastro; SILVA, Edileuza Fernandes da (org.). A escola mudou: que mude a formação dos professores! Campinas: Papirus, 2010. p. 35-60.

CABERO, Julio (dir.) et al. Formación del profesorado universitario en estrategias metodológicas para la incorporación del aprendizaje en red en el Espacio Europeo de Educación Superior (EEES). Píxel-Bit. Revista de Medios y Educación, Sevilha, n. 27, p. 11-29, jan. 2006. Disponível em: https://recyt.fecyt.es/index.php/pixel/article/ view/61267. Acesso em: 19 jul. 2020.

CANÁRIO, Rui. Educação de adultos: um campo e uma problemática. Lisboa: Educa, 2000.

CANÁRIO, Rui. A escola tem futuro? Das promessas às incertezas. Porto Alegre: Artmed, 2006.

CONSELHO DE REITORES DAS UNIVERSIDADES PORTUGUESAS. Por uma formação inicial de professores de qualidade. Lisboa: CRUP, 2000.

COSTA, Fernando Albuquerque (coord.) et al. Competências TIC: estudo de implementação. Vol. I. Lisboa, Portugal: GEPE - Ministério da Educação, 2008. 
COSTA, Fernando Albuquerque (coord.) et al. Competências TIC: estudo de implementação. Vol. II. Lisboa, Portugal: GEPE - Ministério da Educação, 2009.

CRESWELL, John W. Projeto de pesquisa: métodos qualitativo, quantitativo e misto. 3. ed. Porto Alegre: Artmed, 2011.

CUNHA, Maria Isabel da. Aportes teóricos e reflexões da prática: a emergente reconfiguração dos currículos universitários. In: MASETTO, Marcos Tarcisio. Docência na universidade. São Paulo: Papirus, 2003. p. 27-38.

DÍAZ, Pilar Mingorance. Metodología de enseñanza universitária: la mejoria de la situación de enseñanza en las aulas universitárias. In: RUIZ, Cristina Mayor (coord.). Enseñanza y aprendizaje en la educación superior. Sevilha: Octaedro, 2003. p. 113-140.

ENOCHSSON, Ann-Britt. ICT in initial teacher training. Sweden: OECD, 2009. Disponível em: https://www.oecd.org/sweden/45046846.pdf. Acesso em: 19 jul. 2020.

EUROPEAN COMMISSION (EC). The Bologna Declaration on the European space for higher education: an explanation. [Espanha]: EC, 1999.

EUROPEAN COMMISSION (EC). Conference of Ministers responsible for Higher Education in Prague. Prague: EC, 2001. Disponível em: http:/www.weebly.com/ uploads/1/2/3/3/12332890/2001_-_comunicado_de_praga.pdf. Acesso em: 19 jul. 2020.

EUROPEAN COMMISSION (EC). Programa de trabalho pormenorizado sobre o seguimento dos objectivos dos sistemas de educação e formação. Barcelona: EC, 2002. Disponível em: http://www3.uma.pt/nunosilvafraga/wp-content/uploads/2008/12/ programa-de-trabalho-sobre-o-seguimento-dos-objectivos-dos-sistemas-de-educacaoe-de-formacao-na-europa.pdf. Acesso em: 19 jul. 2020.

EUROPEAN COMMISSION (EC). Realising the European Higher Education. Communiqué of the Conference of Ministers responsible for Higher Education in Berlin. Berlin: EC, 2003. Disponível em: http://www.ehea.info/media.ehea.info/file/2003 Berlin/28/4/2003_Berlin_Communique_English_577284.pdf. Acesso em: 19 jul. 2020.

EUROPEAN COMMISSION (EC). Conference of Ministers responsible for Higher Education in Bergue. Bergue: EC, 2005. Disponível em: http://www.ehea.info/media. ehea.info/file/2005_Bergen/52/0/2005_Bergen_Communique_english_580520.pdf. Acesso em: 19 jul. 2020 .

EUROPEAN HIGHER EDUCATION AREA (EHEA). Budapest-Vienna Declaration on the European Higher Education Area. Budapest, Viena: EHEA, 2010. Disponível em: http://www.ehea.info/Upload/document/ministerial_declarations/Budapest_Vienna Declaration_598640.pdf. Acesso em: 19 jul. 2020.

EUROPEAN LIFELONG LEARNING INDICATORS (ELLI). Developing a conceptual framework working paper: version 2.0. [s.l.]: ELLI, 2008.

EUROPEAN POLITICAL CONTEXT (EPC). Teachers' professional development: Europe in international comparison. [s.l.]: EPC, 2011. 
EUROPEAN QUALIFICATIONS FRAMEWORK (EQF). European Commission. Education \& training: Lifelong Learning Policy. [s.l.]: EQF, 2008.

EUROPEAN UNIVERSITY ASSOCIATION (EUA). EUA Annual Report 2002. Geneva \& Brussels: EUA, 2002.

EUROPEAN UNIVERSITY ASSOCIATION (EUA). Institutional evaluation programme: University of Lisbon. Lisbon: EUA, 2008.

EUROPEAN UNIVERSITY ASSOCIATION (EUA). Survey on Master Degrees and Joint Degrees in Europe. Lisbon: EUA, 2009.

EURYDICE. Eurybase: o sistema educativo em Portugal. Lisboa: Direcção Geral de Educação e Cultura, 2006.

FORMOSINHO, João. A formação prática de professores: da prática docente na instituição de formação à prática pedagógica nas escolas. In: CAMPOS, Bartolo Paiva. Formação profissional de professores no Ensino Superior. Porto: Porto Editora, 2001. p. 46-64.

GRIX, Jonathan. Introducing students to the generic terminology of social research. Politics, [s.l.], v. 22, n. 3, p. 175-186, set. 2002.

LOPES, Amélia. De uma escola a outra: temas para pensar a formação inicial de professores. Porto: Afrontamento/CIIE, 2007.

LUNDGREN, Ulf P. Formulación de la política educativa: descentralización y evaluación. In: PEREYRA, Miguel et al. (org.). Globalización y descentralización de los sistemas educativos. Barcelona: Pomares Ediciones, 1996.

MASETTO, Marcos Tarcisio. Docência universitária: repensando a aula. In: TEODORO, Antonio; VASCONCELOS, Maria Lucia (org.). Ensinar e aprender no Ensino Superior: por uma epistemologia da curiosidade na formação universitária. 2. ed. São Paulo: Mackenzie e Cortez, 2005. p. 79-106.

MOGALAKWE, Monageng. The use of documentary research methods in social research. African Sociological Review, [s.l.], v. 10, n. 1, p. 221-230, 2006.

NATIONAL COUNCIL OF EDUCATIONAL RESEARCH AND TRAINING (NCERT). National Focus Group on Teacher Education for Curriculum Renewal. New Delhi: NCERT, 2010. 39 p. Disponível em: http://www.ncert.nic.in/new_ncert/ncert/rightside/ links/pdf/focus_group/teacher_edu_final.pdf. Acesso em: 19 jul. 2020.

NATIONAL COUNCIL FOR TEACHER EDUCATION (NCTE). National curriculum framework for teacher education towards preparing professional and human teacher. New Delhi: NCTE, 2009.

NICKEL, Fausta Araújo. Docência: desafios, enfrentamentos e conquistas. In: BEHRENS, Marilda Aparecida (org.). Docência universitária na sociedade do conhecimento. Curitiba: Champagnat, 2003. p. 61-84. 
NÓVOA, António. Os professores e a sua formação. Lisboa: Dom Quixote, 1992.

NÓVOA, António. Espaço público da educação: imagens, narrativas e dilemas. In: NÓVOA, António et al. Espaços de educação, tempos de formação. Lisboa: Fundação Calouste Gulbenkian, 2002.

NÓVOA, António. O regresso dos professores. In: PRESIDÊNCIA PORTUGUESA DO CONSELHO DA UNIÃO EUROPEIA, 2007, Lisboa. [Conferência]. Desenvolvimento profissional de professores para a qualidade e para a equidade da aprendizagem ao longo da Vida. Lisboa: UE; Ministério da Educação, 2007. Disponível em: http:// escoladosargacal.files.wordpress.com/2009/05/regressodosprofessoresantonionovoa.pdf. Acesso em: 10 jul. 2020. NÓVOA, António. Professores: imagens do futuro presente. Lisboa: Educa, 2009.

NYGAARD, Claus; HØJLT, Thomas; HERMANSE, Mads. Learning-based curriculum development. Higher Education, [s.l.], v. 55, p. 33-50, jan. 2008.

PACHECO, José Augusto. Políticas curriculares descentralizadas: autonomia ou recentralização? Educação \& Sociedade, Campinas, v. 21, n. 73, p. 139-161, dez. 2000.

PALMERO, Julio Ruíz. Evolución de la implementación de las TIC por parte de las administraciones educativas. In: ARIZA, José Manuel Ríos; PALMERO, Julio Ruíz. Competencias, TIC e innovación: nuevos escenarios para nuevos retos. Sevilla: Eduforma, 2011. p. 40-56.

PINTO, Neuza Bertoni. Saberes docentes e processos formativos. Revista Diálogo Educacional, Curitiba, v. 2, n. 3, p. 43-57, jan./jun. 2001.

PONTE, João Pedro da. Os desafios do Processo de Bolonha para a formação inicial de professores. Revista da Educação, [s.l.], v. 14, n. 1, p. 19-36, 2006.

PORTUGAL. Ministério da Educação e Ciência. Decreto-Lei n. ${ }^{\circ}$ 194/99. Cria e regula o sistema de acreditação dos cursos de formação inicial de educadores de infância e professores da educação básica e do ensino secundário. Diário da República, n. 131/1999, Série I-A de 1999-06-07. Disponível em: https:/dre.pt/pesquisa/-/search/309481/details/ maximized. Acesso em: 9 set. 2020.

PORTUGAL. Ministério da Educação e Ciência. Decreto-Lei n. ${ }^{\circ}$ 6/2001. Aprova a reorganização curricular do ensino básico. Diário da República, n. 15/2001, Série I-A de 2001-01-18. Disponível em: https://dre.pt/pesquisa/-/search/338986/details/maximized. Acesso em: 9 set. 2020.

PORTUGAL. Ministério da Educação e Ciência. Decreto-Lei n. o 240/2001. Aprova o perfil geral de desempenho profissional do educador de infância e dos professores dos ensinos básico e secundário. Diário da República, n. 201, p. 5569-5572, 30 ago. 2001. Disponível em: https://re.pt/home/-/dre/631837/details/maximized. Acesso em: 19 jul. 2020. 
PORTUGAL. Ministério da Educação e Ciência. Decreto-Lei n. ${ }^{\circ}$ 43/2007. Aprova o regime jurídico da habilitação profissional para a docência na educação pré-escolar e nos ensinos básico e secundário. Diário da República, n. 38, p. 1320-1328, 22 fev. 2007. Disponível em: https://dre.pt/pesquisa/-/search/517819/details/maximized. Acesso em: 19 jul. 2020.

PORTUGAL. Ministério da Educação. Decreto-Lei n. ${ }^{\circ}$ 79/2014. Aprova o regime jurídico da habilitação profissional para a docência na educação pré-escolar e nos ensinos básico e secundário. Diário da República, n. 92/2014, Série I de 2014-05-14. Disponível em: https://dre.pt/pesquisa/-/search/25344769/details/maximized. Acesso em: 9 set. 2020.

PRENDES, Maria Paz; CASTAÑEDA, Linda; GUTIÉRREZ, Isabel. ICT competences of future teachers. Scientific Journal of Media Literacy, [s.l.], v. 35, n. 18, p. 175-181, 2010.

QUINTÁS, Alfonso López. Literatura y formación humana. Madrid: San Pablo, 1997.

RAJU, Jaya; RAJU, Reggie. Descriptive and subject cataloguing. Oxford: Chandos, 2006.

RUIZ, María Ángeles Martínez; PARÉS, Narciso Sauleda. La investigación basada en el diseño del crédito europeo. In: RUIZ, María Ángeles Martínez; CARRASCO-EMBUENA, Vicente (ed.). Investigar en diseño curricular: redes de docência en el Espacio Europeo de Educación Superior. Alicante: Marfil, 2005. p. 7-22.

SÁNCHEZ LUNA, Blanca Estela. Catalogación por materia. In: FIGUEROA ALCÁNTARA, Hugo Alberto; RAMÍREZ VELÁSQUEZ, César Augusto (org.). Organización bibliográfica y documental. México: CUIB-UNAM, 2004. p. 83-103.

SANTOS, Lucíola. Pluralidade de saberes em processos educativos. In: CANDAU, Vera Maria et al. (org.). Didática, currículo e saberes escolares. Rio de Janeiro: DPA, 2000. p. 46-59.

SCHÖN, Donald. The reflective practitioner: how professional think in action. Avebury: Aldershot Hants, 1983.

SHULMAN, Lee. Knowledge and teaching: foundations of the new reform. Harvard Educational Review, v. 57, n. 1, p. 1-23, apr. 1987.

SOUSA, Jesus Maria. Teacher education in Portugal: analysing changes using the ATEE-RDC19 scenario methodology. European Journal of Teacher Education, [s.l.], v. 26, n. 1, p. 77-86, 2003.

TARDIF, Maurice. Saberes docentes e formação profissional. 12. ed. Petrópolis, RJ: Vozes, 2011.

TAYLOR, Dena. The literature review: a few tips on conducting it. Toronto: University of Toronto, 2002. Disponível em: https://advice.writing.utoronto.ca/wp-content/uploads/ sites/2/literature-review.pdf. Acesso em: 19 jul. 2020.

TORRES, Patrícia Lupion. Algumas vias para entretecer o pensar e o agir. Curitiba: Senar, 2007. 
UNESCO. Open and distance learning trends, policy and strategy considerations. Paris: UNESCO, 2002.

UNESCO. Comunicado final da Conferência Mundial sobre Ensino Superior 2008. Paris: UNESCO, 2009. UNIVERSIDADE DE LISBOA. Despacho n. ${ }^{\circ}$ 6967/2010. Constituição do Conselho de Garantia da Qualidade. Diário da República, série 2, n. 76, p. 20544-20545, 20 abr. 2010. Disponível em: https://livrozilla.com/doc/837312/ despacho-n. ${ }^{\circ}$-6967-2010---universidade-de-lisboa. Acesso em: 19 jul. 2020.

WHEELER, Steve. Digital learning futures. Plymouth: Plymouth University, 2012.

Texto recebido em 19/07/2020.

Texto aprovado em 24/08/2020. 